\title{
Valuation of travel time in free-flow and congested traffic and its reliability-estimates for Czech Republic
}

\author{
Vojtěch Máca ${ }^{a}$, Markéta Braun Kohlováa \\ ${ }^{a}$ Charles University Environment Centre, J. Martiho 2, Prague 6, 16000, Czech Republic
}

\begin{abstract}
A prerequisite for any monetary estimation of economic losses arising from traffic congestion is a reliable estimate of the value of travel time. Although the available evidence from abroad reveals significant differences in the values of individual components of time travel, specific valuations of travel time are rather rare in the Czech Republic. The aim of this paper is to expand the data base in the Czech Republic by presenting selected estimates of the travel time components for Czech drivers and passengers. Specifically, we elaborate on the value of travel time and time spent in congestion for medium-long domestic routes (represented by the Prague-Brno route). The results of our valuation study $(N=602)$ show that the value of travel time spent in congestion is almost twice as high as the value of travel time in free-flow traffic and suggest that the reduction of congestion and of the variation in travel time in general will bring significant economic benefits compared to shortening travel time in free-flow traffic. This evidence confirms the importance of distinguishing between different components of travel time when assessing the benefits of transport infrastructures. Importantly, our estimates of the value of travel time are much lower than those officially endorsed by Czech Ministry of Transport (MoT) for analysing benefits of new transport infrastructure.
\end{abstract}

KEYWORDS: Random utility model; value of travel time; reliability of travel time; stated preferences

\section{INTRODUCTION}

A calculation of the value of travel time is a prerequisite for any monetary estimation of economic losses arising from traffic congestion. The aggregated travel time savings for the mobile population expressed in money is the most reported benefit of any new trans- port infrastructure development. Since the 1960s, a large number of studies have been carried out to measure the value of travel time (VoT), and gradually also to distinguish its different components. Thus, time spent in a vehicle, time for access/egress, waiting, transfer or time in congestion have been identified (Small, 2012). In addition specific values exist for users of different transport modes, journey length and purposes.

Although the available evidence from abroad shows large differences in the values of individual travel time components, and in spite of the fact that the stated preference methods have been successfully used in the Czech Republic in the valuation of environmental goods, specific values of travel time and individual travel time components are rather rare in the Czech Republic. The value of travel time for Czechs' long-distance irregular journeys was estimated at 30 EUR per hour (about $738 \mathrm{CZK}$ ) in the KITE study (Frei \& Axhausen, 2009), and by Šenk, Biler, \& Daňková (2012) for leisure trips by car at $56 \mathrm{CZK} /$ hour (weekend trips) and $116 \mathrm{CZK} /$ hour (holiday trips). Other more recent studies reported $171 \mathrm{CZK}$ /hour for business trips by bus (Šmerdová, 2016) and $167 \mathrm{CZK} /$ hour by train (Moravec, 2016). Note however that these estimates - both findings of student theses - are based on surveys on limited samples $(\mathrm{N}=111$ and $\mathrm{N}=101$, respectively). Two other studies reported the value of time for urban travel at $73 \mathrm{CZK} /$ hour and $36 \mathrm{CZK} /$ hour for car and public transport respectively (Kašík, 2011), and at $112 \mathrm{CZK} /$ hour (Braun Kohlová, 2011), which is typically lower than the value for intercity travel by up to $30 \%$ (USDOT, 2011). When valuing business trips, wage equivalent is most often used in the Czech Republic. For example the methodology employed by the MoT uses the value of CZK 600 per hour (MoT, 2017).

This paper has three objectives: i) to provide specific estimates of the value of travel time and reli- 
ability of travel time for the Czech Republic; (ii) demonstrate with empirical data the evidence that transport policy tools will have different effects depending on which component of travel time and which user group is affected, and (iii) popularize methods which allow us to examine individual decisions based on the characteristics of transport alternatives that are otherwise difficult to measure.

\section{METHODS AND DATA}

The Random Utility Model (RUM; McFadden, 1974; Ben-Akiva \& Lerman, 1985; Train, 2009) is the classic conceptual framework for exploring how travel time and reliability of travel time influences choices concerning travel mode or route. The model assumes that people compare available alternatives based on the logic of allocating limited resources, in particular time and money, and the least effort exerted. Choosing one specific alternative is the result of comparing how much the alternative in question is advantageous compared to other alternatives in terms of meeting an individual's needs. The measure of the comparison of alternatives is the so-called utility and an outside observer (analyst) cannot observe these utilities with certainty but treats them as random variables. Hence the model is called the random utility model.

To explore the value of travel time, we used the stated preference method (Louviere, Hensher, $\&$ Swait, 2000) on the choice of a hypothetical route for the journey between Prague and Brno. This method is appropriate due to the RUM's need for characteristics of both chosen and non-chosen alternatives, and the difficulty of obtaining such data from real (so called revealed) choices, especially for the individual components of travel time. Stated preferences were explored in two independent choice experiments (CE1 and CE2). Each experiment comprised a sequence of choices between two alternative routes characterized by total trip time, price, and one of the travel time components examined. In CE1, the last attribute was either the average delay during a journey by train or time spent in congestion while traveling by car or bus (see Table 1). Each respondent obtained a version of this attribute depending on the travel mode used on her/his reported most recent trip on this route. In CE2 we used the mean-variance approach in order to examine how reliability of travel time affects the route choice (Black \& Towriss, 1993; Jong, Tseng, Kouwenhoven, Verhoef, \& Bates, 2007;
Ramjerdi, Flügel, Samstad, \& Killi, 2010; Small, Noland, Chu, \& Lewis, 1999). In the choice experiment travel time reliability was manipulated through the variance of travel time; specifically each participant was presented with five possible journey durations which have the same probability when using the respective travel mode. The variance of travel time was subsequently analysed as a standard deviation, i.e. the square root of the variance. Each choice experiment consisted of eight choice tasks, and were part of one electronic questionnaire.

The levels of attributes of travel time and cost in the experiment were set as a percentage change in the respective attribute of the respondent's most recent trip reported in the introductory part of the questionnaire (Bradley's design, see de Jong et al., 2007). For example the time spent in congestion (or average delay for a train journey) in an experimental alternative may have taken one of five levels $(0 \%,+2 \%,+4 \%$, $+8 \%$ and $+12 \%$ ), hence for a 150 minute journey, this represents between 0 and 18 minutes. The levels of attributes were not always symmetrical in order to make alternatives as realistic as possible. Each respondent was randomly assigned a specific variant of the sequence of choice situations, (so-called block), and order of choices within the sequence. Such a design with attribute levels based on actual behavior diminishes one of the main shortcoming of statedpreference surveys, i.e. questionable ecological validity of the hypothetical choice situations.

Data were collected in a web survey by means of an electronic questionnaire between November 2010 and April 2011. The target population were adult residents of the Prague and Brno agglomerations who had traveled on the route Prague-Brno in either direction at least once in the previous half year. The recruitment quotas aimed at approximately proportional representation of three transport modes (car, bus, and train), and business and non-business purposes within each mode. Respondents were recruited by the SC\&C agency. The resulting sample consists of 602 respondents which comprises an effective sample of 4816 choices for each choice experiment (1688, 1576 and 1552 choices for car, train and bus segments respectively). Descriptive statistics of actual travel time by mode are shown in Table 1 .

Data from the two choice experiments were analysed separately by the binary logistic model. Random parameter logistic regression models were estimated using an mlogit package in R statistical language (R Core Team, 2011; Croissant, 2011a). 
Table 1. Descriptive statistics of actual travel times by travel mode.

\begin{tabular}{ccccccc}
\hline Mode & N & Mean & Median & Std. dev. & Minimum & Maximum \\
\hline Car & 211 & $2: 47$ & $2: 30$ & $2: 04$ & $1: 15$ & $10: 00$ \\
Train & 197 & $3: 01$ & $2: 46$ & $1: 33$ & $1: 20$ & $6: 43$ \\
Bus & 194 & $2: 39$ & $2: 30$ & $1: 40$ & $1: 23$ & $9: 30$ \\
\hline
\end{tabular}

Table 2. An example of the experimental choice (for car / bus and all travel modes).

\begin{tabular}{lll}
\hline If respondent used ... & car or bus & \\
\cline { 2 - 3 } & Journey $A$ & Journey B \\
\hline Costs “per person / car" & 250 CZK & 350 CZK \\
Total travel time & $2: 30$ hours & $2: 00$ hours \\
Time spent in congestion & $0: 30$ hours & $0: 00$ hours \\
\hline If respondent used ... & any transport mode & \\
\cline { 2 - 3 } & Journey $A$ & Journey B \\
\hline Costs "per person / car" & 250 CZK & 350 CZK \\
Possible travel time & $1: 45$ hours & $1: 30$ hours \\
& $2: 00$ hours & $1: 45$ hours \\
& $2: 30$ hours & $2: 00$ hours \\
& $2: 45$ hours & $2: 15$ hours \\
\hline
\end{tabular}

Note. 1 euro $=24.6 \mathrm{CZK}$ (average annual exchange rate of the Czech National Bank for 2011)

Correlation of error terms stemming from repeated responses from the same respondent was accounted for using panel techniques. Based on the observed choices and the known attributes of the available alternatives, we estimated the coefficients describing the effects of the attributes on choice probability (Ben-Akiva \& Lerman, 1985 or Train, 2003), provided in detail in Appendix B. Thus we obtained the coefficients of travel cost, travel time, and travel time reliability as well as estimates of the coefficients of different characteristics of the journey and an individual. We used indicators for the frequency of the respective journeys, respondent's income and purpose of the trip that have been well documented to affect the value of travel time (de Jong et al., 2013; Ramjerdi, Flügel, Samstad, \& Killi, 2010; Wardman, Chintakayala, Jong, \& Ferrer, 2012). The value of travel time and value of travel time reliability were then calculated as the ratio of the coefficients of travel time and travel cost and coefficients of travel time reliability and travel cost.

\section{RESULTS}

The estimated average values of travel time and time spent in traffic congestion are presented in Table 2. Estimates for the car drivers/passengers segment confirm well-established evidence that the value of time spent in traffic congestion is higher than that of standard travel time ( 251 vs. $179 \mathrm{CZK} /$ hour, i.e., about $40 \%$ higher). Also, the value of time for business trips and for the segment of frequent drivers and passengers is higher than for non-business trips and the segment of infrequent drivers and passengers. In line with economic theory assumptions, the value of travel time increases with the passenger's income.

The value of travel time spent in traffic congestion also depends on the total journey time. The shorter the journey, the higher the value (loss) per minute spent in congestion than in free-flow conditions (see Small et al., 2012). While for a 200-minute journey, the value of time spent in congestion is $3.28 \mathrm{CZK} / \mathrm{min}$, for a 120-minute trip it rises to $5.47 \mathrm{CZK} / \mathrm{min}$. 
Table 3. Estimated Value of Travel Time for selected segments - Car journey only (CZK/hour).

\begin{tabular}{lllll}
\hline \multirow{2}{*}{ Journey type } & \multirow{2}{*}{ Journey frequency } & \multirow{2}{*}{ Income } & \multicolumn{2}{c}{ Value of Travel Time... } \\
\cline { 3 - 5 } & & high $^{* *}$ & in free-flow & in congestion \\
\hline business & high $^{*}$ & low & 179 & 353 \\
& & high & 180 & 265 \\
\cline { 2 - 5 } & low & low & 144 & 266 \\
& high & high & 167 & 213 \\
\hline non-business & low & 135 & 247 \\
& low & high & 136 & 200 \\
& & low & 114 & 200 \\
& & & 169 \\
\hline
\end{tabular}

Note. *High is a dummy indicator for a person who conducted more than 5 journeys on the respective route and low for a person who conducted maximum of 5 journeys in the last year. ${ }^{* *} \mathrm{High}$ is a dummy indicator for a person with personal income above sample mean (rounded to $18500 \mathrm{CZK}$ )

Table 4. Value of travel time and reliability of travel time (average).

\begin{tabular}{llll}
\hline Mode & $\begin{array}{l}\text { Value of travel time } \\
\text { (CZK/h) }\end{array}$ & $\begin{array}{l}\text { Value of reliability of travel } \\
\text { time }(\mathbf{C Z K} / \mathbf{h})\end{array}$ & Reliability ratio \\
\hline Car & 222 & 181 & 0.81 \\
Train & 77 & 22 & 0.28 \\
Bus & 74 & 40 & 0.53 \\
\hline
\end{tabular}

Note. Reliability of travel time is the standard deviation of the average travel time. Reliability ratio $=$ value of reliability of travel time / value of travel time.

The value of travel time varies according to the travel mode used. It is significantly higher for a car than for train and bus journey (222 CZK/hour vs. 77 and $74 \mathrm{CZK} /$ hour respectively). The value of reliability of travel time, i.e. standard deviation from the average travel time, may be illustrated by the following example of a car journey. Assume that the journey may take one of five possible durations between 120 and 180 minutes and a driver/passenger is willing to pay up to $90 \mathrm{CZK}$ for $100 \%$ certainty of the travel time. The reliability ratio indicates that a car user is willing to accept up to 0.81 minutes of additional travel time to eliminate 1 minute of the standard deviation of total travel time.

The unit cost of travel time reliability is higher for car journeys than for public transport and is lower in the case of all travel modes than the value of average travel time. However, the value of reliability of travel time for a train journey is only half that of a bus trip. From such a low value of reliability, one can assume that - when traveling by train - people are more tolerant to a change of travel time against the schedule.

\section{DISCUSSION}

To examine the value of travel time, we used the stated preference method for a hypothetical journey between the two largest cities in the Czech Republic. The use of this method may provide biased estimates from which we would diverge from actual behaviour due to the fact that we employed a hypothetical situation (Braun Kohlová, 2012, estimated the value of $112 \mathrm{CZK} /$ hour for city journeys by a car a year prior to this data collection).

The results of our study show that the value people attribute to travel time on medium-distance journeys depends on many conditions. It depends if the time is spent in free-flow or congested traffic, or if it encroaches on the time of a subsequent planned activity. Travel time reliability also has a highly positive 
value implying that social benefits can be achieved not only by shortening travel time but also by making it more predictable. The values of all travel time components of business trips are higher than for leisure trips. The results are consistent with existing domestic and foreign evidence (Wardman, Chintakayala, Jong, \& Ferrer, 2012). Notice that some studies show that the value of travel time under specific circumstances can reach both zero and negative values (for work trips by train, see e.g., Lyons, Jain, \& Holley, 2007; and Mokhtarian \& Salomon, 2001). The journey itself can represent an extra benefit and not just the cost of reaching the destination. Such heterogeneity in values of travel time for individuals and various circumstances were taken into account in the models with a random parameter for travel time. The positive values reported in Table 3 and 4 are for the whole sample and imply that travel time is generally perceived as a cost.

The value of travel time by car is significantly higher than for public modes of transport. This is related to the different incomes of people traveling with different travel modes and, in particular, the value that money has for them. If the value of travel time is used in the evaluation of transport policies, it should also be taken into account that the average estimates inaccurately describe the behaviour of outlying groups of passengers. In all estimates, and even with respect to the fact that our analysis is based on 2011 data, our value of travel time is several times lower than the $600 \mathrm{CZK} /$ hour endorsed in MoT's Methodology for Assessing the Economic Efficiency of Transport Projects (MoT, 2017). Other more recent estimates are not comparable with this value either. Šmerdová (2016) reports $171 \mathrm{CZK} /$ hour for business trips by bus, Moravec (2016) $167 \mathrm{CZK} /$ hour by train, and Šenk and colleagues (2012) for leisure trips by car $56 \mathrm{CZK} /$ hour and $116 \mathrm{CZK} /$ hour.

The mean-variance approach to valuation of travel time reliability is the most common approach, mainly on practical grounds. The approach makes it easy to compute required variables and produces a single measure, i.e. the value of reliability, compared to scheduling models (Carrion \& Levinson, 2012). Our estimated reliability ratios of travel time are in line with the estimates ranging from 0.1 to 2.51 reported in the review by Carrion and Levinson (2012) and in newer European studies (de Jong et al., 2013; Ramjerdi et al., 2010). Yet, as the review by Carrion and Levinson pertinently notes - and we fully concur with this comment - there is a need to validate that the presentation of variability in travel time truly matches the understanding of such an abstract situation by survey respondents.

It should be noted that the results of our study also have several limitations resulting from the method and data collection. The analysed dataset is neither representative of the target population of medium-distance intercity journeys or of the population of drivers and passengers on the Prague-Brno route. The usual sociodemographic characteristics which would allow us to use a quota selection at least, were not known for either of these populations. Neither modal split was known for this type of journeys. That is why we used a qualification criterion in the form of at least one such journey in the previous half-year. The specificity of the sample is also evident from the $30 \%$ share of university graduates.

The data in our study were collected through a web based survey. Even if such a method of data collection is the only feasible way when the research design includes individual specific choice situations and is therefore broadly used in various research contexts (e.g. Krantz \& Dalal, 2010; Ramjerdi et al., 2010 or Daziano, Waygood, Patterson, \& Braun Kohlová, 2017) it raises issues regarding the external validity of the results (cf. Ramsey, Thompson, McKenzie, \& Rosenbaum, 2016). Only a population with reliable internet access was recruited which might have affected the representativeness of the sample with respect to respondents' age, education and income (ČSÚ, 2010). Access to internet is greater among younger people, people with a higher level of education and income (ČSÚ, 2010). However, these are also characteristics that explain travel behaviour (ČSÚ, 2011). While the characteristics of middle age, higher levels of education and economic activity of the people in our sample presumably increase the estimated value of travel time, the lower participation of high-income respondents, common for all survey methods, as well as young age has the opposite effect. Another possible downward effect of a web based survey on estimated value of time has been documented in a Dutch study (Kouwenhoven et al., 2014), originally conducted on an internet panel of respondents. When the survey was repeated with en-route recruitment it was found that persons with a lower value of time (in every socio-economic segment) have a higher probability of becoming a member of an internet panel. For the above mentioned reasons generalization of our results or aggregation over the national population should be done with caution. 


\section{CONCLUSIONS}

The stated-preference study has revealed that the value people attribute to travel time on medium-distance journeys depends on many conditions. It depends if the time is spent in free-flow or congested traffic or what is the purpose of the journey. Travel time reliability also has a highly positive value. Our results thus imply that social benefits can be achieved not only by shortening travel time but also by making it more predictable. Still, our value of travel time is several times lower than the value endorsed in MoT's Methodology for Assessing the Economic Efficiency of Transport Projects.

Acknowledgements: This paper was written thanks to the institutional support of Charles University in the program PROGRESS - Q16 Environmental Sciences. The survey described here was conducted as a part of research grant CG712-111-520 "Quantification of external costs of transport in the Czech Republic" funded by Ministry of Transport.

\section{REFERENCES}

Ben-Akiva, M. E., \& Lerman, S. R. (1985). Discrete choice analysis: Theory and application to travel demand. Cambridge, MA: MIT Press.

Black, I. G., \& Towriss, J. G. (1993). Demand effects of travel time reliability. Cranfield: Centre for Logistics and Transportation, Cranfield Institute of Technology.

Braun Kohlová, M. (2012). Cesty městem: $O$ racionalitě každodenního cestování. Praha: Sociologické nakladatelství (SLON).

Carrion, C., \& Levinson, D. (2012). Value of travel time reliability: A review of current evidence. Transportation Research Part A: Policy and Practice, 46(4), 720-741. https://doi.org/10.1016/j. tra.2012.01.003

Croissant, Y. (2011). mlogit: multinomial logit model. R package version 0.2-1. https://CRAN.R-project.org/package=mlogit

ČSÚ. (2011). Dojiždka do zaměstnání a škol podle Sčitání lidu, domů a bytů - Česká republika - 2011. Český statistický úřad. (15 May 2019). Retrieved from https://www.czso.cz/csu/czso/ dojizdka-do-zamestnani-a-skol-podle-scitani-lidu-domu-abytu-2011-ceska-republika-2011-6elqhrcwol

ČSÚ. (2010). Informační společnost v čislech 2010. Český statistický úrad. (15 May 2019). Retrieved from https://www.czso. cz/csu/czso/informacni_spolecnost_v_cislech_2010

Daziano, A. D., Waygood, E.O.D., Patterson, Z., \& Braun Kohlová, M. (2017). Increasing the influence of $\mathrm{CO}_{2}$ emissions information on car purchase. Journal of Cleaner Production, 164. 861-871. doi:10.1016/j.jclepro.2017.07.001

Frei, A., \& Axhausen, K. W. (2009). Report about results: user requirements and indications about demand volumes. KITE a knowledge base for intermodal passenger travel in Europe, Deliverable 8. Zurich: IVT, ETH. https://doi.org/10.3929/ ETHZ-A-005864357

Jong, G. C. de, Tseng, Y., Kouwenhoven, M., Verhoef, E., \& Bates, J. (2007). The Value of Travel Time and Travel Time Reliability Survey Design, Den Haag: Significance \& John Bates.

Jong, G. C. de, Tseng, Y., Kouwenhoven, M., Verhoef, E., Bates, J., Joosten, M., ... Schoemaker, J. (2013). Values of time and reliability in passenger and freight transport in The Netherlands. Report for the Ministry of Infrastructure and the Environment. Den Haag: Significance. Retrieved from https://www.kimnet. nl/publicaties/rapporten/2013/11/18/values-of-time-and-re$\underline{\text { liability-in-passenger-and-freight-transport-in-the-netherlands }}$

Kašík, J. (2011). Valuation of Time in Car and Public Transport:Stated Preferences Research and Pratical Use in Multimodal Modelling in the Czech Republic - The Results of Research and Development Project No.CG721-045-190, presented at the conference External Costs of Transport, Retrieved from https:// www.czp.cuni.cz/czp/images/stories/Vystupy/TranExt/5-Kasik-Valuation_of_Time_in_car_and_public_transport.pdf

Kouwenhoven, M., de Jong, G. C., Koster, P., van den Berg, V. A. C., Verhoef, E. T., Bates, J., \& Warffemius, P. M. J. (2014). New values of time and reliability in passenger transport in The Netherlands. Research in Transportation Economics, 47, 37-49. https://doi.org/10.1016/J.RETREC.2014.09.017

Krantz, J. H., Dalal, R. (2000). Validity of Web-Based Psychological Research. In M. H. Birnbaum, (Ed.). Psychological Experiments on the Internet (pp. 35-60). https://doi.org/10.1016/ B978-012099980-4/50003-4

Louviere, J., Hensher, D. A., \& Swait, J. D. (2000). Stated Choice Methods. Analysis and Applications. Cambridge: Cambridge University Press.

Lyons, G., Jain, J., \& Holley, D. (2007). The use of travel time by rail passengers in Great Britain. Transportation Research Part A: Policy and Practice, 41(1), 107-120. https://doi.org/10.1016/j. tra.2006.05.012

McFadden, D. (1973). Conditional logit analysis of qualitative choice behavior. In P. Zarembka (Ed.), Frontiers in econometrics (pp. 105-142). New York: Academic Press.

Mokhtarian, P. L., \& Salomon, I. (2001). How derived is the demand for travel? Some conceptual and measurement considerations. Transportation Research Part A: Policy and Practice, 35(8), 695-719. https://doi.org/10.1016/S0965-8564(00)00013-6

Moravec, T. (2016). Hodnota úspor cestovního času v České republice. Bachelor's thesis, ESF MU.

MoT. (2017). Rezortní metodika pro hodnocení ekonomické efektivnosti projektů dopravních staveb. Prague: Ministry of Transport.

R Core Team (2016). $R$ : A language and environment for statistical computing. R Foundation for Statistical Computing, Vienna, Austria. https://www.R-project.org/ 
Ramjerdi, F., Flügel, S., Samstad, H., \& Killi, M. (2010). Value of time, safety and environment in passenger transport - Time. Oslo: Transportøkonomisk institutt. (10 October 2018). Retrieved from http://www.toi.no/article29726-29.html

Ramsey, S. R., Thompson, K. L., McKenzie, M., \& Rosenbaum, A. (2016). Psychological research in the internet age: The quality of web-based data. Computers in Human Behavior, 58, 354-360. https://doi.org/10.1016/j.chb.2015.12.049

Small, K. A. (2012). Valuation of travel time. Economics of Transportation, 1, 2-14. https://doi.org/10.1016/j.ecotra.2012.09.002

Small, K. A., Noland, R., Chu, X., \& Lewis, D. (1999). Valuation of Travel-Time Savings and Predictability in Congested Conditions for Highway User-Cost Estimation. Washington D.C.: National Academy Press.

Šenk, P., Biler, S., \& Daňková, A. (2012). Value of Travel Time Savings in the Context of Leisure Travel in the Czech Republic. Transactions on Transport Sciences, 5(4), 215-222. https://doi. org/10.2478/v10158-012-0024-1.

Šmerdová, L. (2016). Hodnota úspor cestovního času v České republice. Bachelor's thesis, ESF MU.

Train, K. E. (2003). Discrete choice methods with simulation. Cambridge: Cambridge University Press.

USDOT (2011). The value of travel time savings: Departmental guidance for conducting economic evaluations, U.S. Department of Transportation (www.usdot.gov). (24 May 2019). Retrieved from www.dot.gov/sites/dot.dev/files/docs/vot_ guidance_092811c.pdf.

Wardman, M., Chintakayala, P., Jong, G. de, \& Ferrer, D. (2012). European Wide Meta-Analysis of Values of Travel Time. Final report to the European Investment Bank. Leeds: University of Leeds. 


\section{APPENDIX A}

Table A1: Sociodemographic and socio-economic characteristics of the survey sample

\begin{tabular}{lccc}
\hline & Mean & Median & Std. dev. \\
\hline Age & 38.56 & 40 & 12.45 \\
Respondent's net monthly income (CZK) & 18571 & 19750 & 13775 \\
\hline Gender - male & & $49.3 \%$ & \\
\hline Education & & $4.65 \%$ & \\
- basic & & $14.12 \%$ & \\
- vocational training & & $50.17 \%$ & \\
- $\quad$ high school diploma & $31.06 \%$ & \\
- college/university degree & 1.26 & 1 & \\
\hline Car ownership (household) & & \\
\hline Company car availability (only respondents in workforce) & & \\
- always & & $14.95 \%$ & \\
- $\quad$ sometimes & & $16.45 \%$ & \\
- never & & $31.89 \%$ & \\
\hline Public transport pre-paid card ownership & & \\
- in Prague & & \\
- in Brno & & $31.06 \%$ \\
in both cities & & $19.27 \%$ \\
\hline
\end{tabular}

\section{APPENDIX B}

\section{Econometric model of value of time in congestion}

The basic model of systematic (indirect) utility for this set-up as suggested by Small et al. (1999) consists of three variables in linear form, mathematically denoted as

$V=\beta_{M} M+\beta_{T} T+\beta_{C} T_{C}+\beta_{V} \sigma_{T}+\beta_{W} \sigma_{C}$

where $M$ is travel cost, $T$ is travel time and $T_{C}$ is travel time in congested conditions, $\sigma_{T}$ and $\sigma_{T C}$ are, respectively, standard deviations of travel time and travel time in congested conditions, and $\beta$ 's are parameters to be estimated. The modelling approach uses random parameter logit estimation (e.g. Train, 2003) to determine the probability of choosing one of the two alternatives presented in each of 8 choice sets. For a given vector of coefficients $\beta_{i}$, the probability that alternative $l$ is chosen for the $k$ th observation of the individual $i$ is (Croissant, 2011):
$P_{i k l}=\frac{e^{\beta_{i} x_{i k l}}}{\sum_{j} e^{\beta_{i} x_{i k l j}}}$

The probability for the chosen probability for the $k$ th observation for the individual $i$ is:

$P_{i k}=\prod_{l} P_{i k l}^{y_{i k l}}$

The joint probability for the $K$ observations of individual $i$ is then:

$P_{i}=\prod_{k} \prod_{l} P_{i k l}^{y_{i k l}}$

The probabilities for the random parameter logit are integrals with no closed form and are conventionally estimated using simulation techniques (see e.g. Train, 2003).

In the regression model for value of time in congestion both trip-specific explanatory variables (i.e. travel cost, travel time and congested time) and in- 
dividual-specific variables (trip purpose, income, trip frequency) were statistically significant, the latter group of explanatory variables increasing explanatory power of the model (LR-test $p<0.001$ )

In the regression model for reliability of travel time trip-specific explanatory variables (i.e. travel cost, travel time and congested time) were all statistically significant, individual-specific variables (not shown here) were significant only for car trips and trip purpose was also significant for trips by bus.

\section{Econometric model of value of travel time reliability}

In the second experiment respondents were faced with a choice between two alternatives described by travel costs and 5 possible travel times. In the mean variance approach the model is

$V=\beta_{M} M+\beta_{T} T+\beta_{R} R_{T}+\beta_{V} \sigma_{T}+\beta_{W} \sigma_{R}$

where $M$ is travel cost, $T$ is expected travel time, $R_{T}$ is reliability of travel time, $\sigma_{T}$ is standard deviation of travel time and $\sigma_{R}$ is standard deviation of travel time reliability, and $\beta$ 's are parameters - marginal utilities of cost, travel time and variability - to be estimated. Again, random parameter (mixed) logit was used to estimate the parameters of interest.

Table B1: Logistic regression model of time in congestion (journeys by car)

\begin{tabular}{lcc}
\hline attribute & parameter estimate & std. error \\
\hline travel cost & $-0.0215^{* * *}$ & 0.0016 \\
travel time & $-0.0486^{* * *}$ & 0.005 \\
time in congestion & $-0.0719 * * *$ & 0.0109 \\
travel cost * work travel & $0.0053^{* * *}$ & 0.0012 \\
travel cost ${ }^{*}$ low income & $-0.004^{* *}$ & 0.0013 \\
travel cost * frequent & $0.004^{* *}$ & 0.0014 \\
$\sigma$ travel time & $0.064^{* * *}$ & 0.0065 \\
$\sigma$ time in congestion & $0.113 * * *$ & 0.0188 \\
log-likelihood & -797.87 & 0.31 \\
adj. $\rho^{2}$ & & \\
\hline
\end{tabular}

Note: Significance levels: 0 ‘***’ $0.001^{(* *)} 0.01^{(*)} 0.05$

Table B2: Logistic regression model of travel time reliability

\begin{tabular}{|c|c|c|c|c|c|c|}
\hline \multirow{2}{*}{$\begin{array}{l}\text { mode } \\
\text { attribute }\end{array}$} & \multicolumn{2}{|c|}{ car } & \multicolumn{2}{|c|}{ train } & \multicolumn{2}{|c|}{ bus } \\
\hline & $\begin{array}{c}\text { parameter } \\
\text { estimate }\end{array}$ & std. error & $\begin{array}{c}\text { parameter } \\
\text { estimate }\end{array}$ & std. error & $\begin{array}{c}\text { parameter } \\
\text { estimate }\end{array}$ & std. error \\
\hline travel cost & $-0.0126 * * *$ & 0.0005 & $-0.0415 * * *$ & 0.0023 & $-0.0492 * * *$ & 0.0028 \\
\hline travel time & $-3.4661 * * *$ & 0.1274 & $-0.0531 * * *$ & 0.0047 & $-0.0604 * * *$ & 0.0052 \\
\hline sd of travel time & $-5.0628 * * *$ & 0.2389 & $-0.015 * * *$ & 0.0023 & $-0.0326 * * *$ & 0.0029 \\
\hline$\sigma$ travel time & $0.8911 * * *$ & 0.1029 & $0.0415 * * *$ & 0.0066 & $0.0462 * * *$ & 0.0072 \\
\hline$\sigma$ sd of travel time & $-1.8903 * * *$ & 0.1333 & $0.0415 * * *$ & 0.0037 & $0.0525 * * *$ & 0.0042 \\
\hline log-likelihood & -997.95 & & -892.3 & & -877.51 & \\
\hline $\operatorname{adj} . \rho^{2}$ & 0.232 & & 0.2699 & & 0.2708 & \\
\hline
\end{tabular}

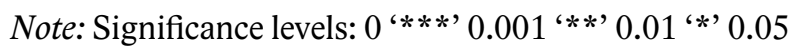

